\title{
Research of Public Accessibility of the Drug Promotion Information in the Russian-Language Internet
}

\author{
Roman Dremliuga \\ Associate professor of the School of Law of the Far Eastern Federal University (Vladivostok, Russia). PhD (Law) \\ dreamluck@yandex.ru, dremliuga.ri@dvfu.ru
}

\section{Doi:10.5901/mjss.2015.v6n3s1p540}

\begin{abstract}
The Internet spreading harmful information has a huge impact on drug situation. We aimed to estimate the incidence of illicit drug promotion and propose among Internet-users. Also we wanted to ascertain a public mind about the jeopardy of information mentioned above and the necessity of crime liability institution for spreading such data. According to received data the Internet sites aimed at drug addicts become more accessible for the last seven years. The harmful information in the Internet is a real threat. The dangerous pages promoting and proposing drug is widely spread and available in the Global net. Russian society claims crime liability for spreading this information.
\end{abstract}

Keywords: drug prevention; Internet; drug promotion, spreading of drug information.

\section{Introduction}

Only small circles of specialists knew drug issue in the beginning of $20^{\text {th }}$ century but then it turned into global international problem threatening all world community. Nowadays drug issue is encouraged by revolution in spreading of information. Everybody can read about drugs, order drugs, find recipe of production drugs and etc. in the Internet. Also the Internet helps to popularize drug consumption, to involve new drug users and to do it with perfect impunity. Although the Internet is an effective tool to struggle against drug problem, it offers sufficient advantages to criminals.

The Russian-language Internet is filled with any kind of harmful information, an internet-user can find racist slogans (For example: http://soprotivlenie.marsho.net/), obscene video and photos as well as the promotion of drugs use. Many specialists concern that it leads to destructive behavior especially among teenagers (Aloyan, 2012). The information about drugs is more dangerous than other because drug using related with huge illegal market (Romanova, 2008) requiring big promotion, but advertising of nonmedical use is prohibited and incomparable opportunity to promote drug in the Internet. Also a big risk links to distribution of the formulas for the drug producing. For example, everybody can find in the Internet description of producing process of methamphetamine analog that isn't detected as drug by modern law enforcement tests and there is no liability for producing and spreading this substance (Boeri, Gibson, Harby, 2009), or can buy on-line legal substances which have narcotic action (Forsyth, 2012). You can even get illegal substance through the Internet (McElrath, O'Neill, 2011). Finally, most dangerous thing is that narcotist can get a wrong recipe in the Internet and prepare more harmful substance (Tupper, 2008).

There is no official statistics of drug crimes and spreading drug information in the Russia-language Internet because it is technically difficult to analyze all sites concerning drugs. In addition, the survey of the sites requires review of the content, it needs enormous human resources. But most part of sites is little attended and, if a researcher wants to know which site is really dangerous he should dissect most available and popular sites. Nowadays the Internet community often uses search engines to find necessary information and it is significant to ascertain that harmful information about drug is very accessible. For example, if somebody wants to generate drugs how many efforts it requires to find recipe in the Internet.

\section{Experimental}

There we researched results of requests to the two search engines in 2005 and 2012 (They were rambler.ru and yandex.ru). All requests were Russian-language and engines were from "ru" domain. To survey we used content analysis of the sites which links were generated by search engines. Every time we analyzed the first one hundred links because usually subsequent links were not browsed by search engine users. Goal of this analysis was to clarify that it could be 
easy to find information about drug supply and drug production or probably to find just media site. Most significant issue was to understand how accessible is for common users to find this information. The question which we asked is what role of the Internet was in promotion of drugs. Also our survey tries to find unintentional promotion of the drugs, for example, if we find interview of some celebrities who use drugs, we mark this site as perhaps promoting. According opinion of many Russian psychologists and criminologists, publication prompts drug use in following cases: usage of wrong or misleading terminology in sphere of drugs, for example dividing of drugs on "light" and "hard" because they are drugs in both cases, including people who became successful but used drugs, praising drugs in movies, songs and other commercial works, publication of information about high income of drug dealers, promotion of non-medical drug use legalization.

Analysis of the resource harmfulness was provided by psychologist of the Drug addiction prevention center of the Far Eastern Federal University (prevention.wl.dvfu.ru). They made a conclusion about jeopardy of information posted in the sites on the ground of high practical skills received during work in the center.

Also we asked 363 persons about the presence of harmful information in the Internet. They were citizens of the Far East of the Russian Federation who has own opinion about this issue.

\section{Results}

First request was on the $17^{\text {th }}$ May 2005 "sell drugs" (in the Russian language), we got interesting result after providing content analysis of first hundred links generated by first search-engine (yandex.ru). In 90 percent of cases it was just Internet-media pages but 12 percent were provocative materials inciting probably drug use. It was significant that 3 percent were sites with information about making and selling of drugs. The rest of the pages found by search-engine were either sites unlinked with drugs or medical portals where drugs were mentioned in medical context.

When we repeated request to the second search-engine (rambler.ru) there were just 2 percent of sites with information about making and selling of drugs ("sites for drug addicts"). 11 percent of provocative materials included 81 percent of Internet-media pages. It was menacing because if you want to find drugs in the Internet you can do it easily. Even if you find some helpful information, you can simply get provocative materials.

Second request was "make drugs" (in Russian language). As regards Internet-media sites results of search by "yandex.ru" were almost the same, 87 percent of all and 10 percent of provocative information. But at least $5 \%$ percent were links to drug addict dictionary (This book is wide spread in the Russian Internet) where everybody could read the composition of drugs and the method of their production, native slang and many promotion messages. The results of "rambler" search were 2 percent of sites for drug addicts and 11 percent of provocative pages.

Moreover, 48 sites of drug addicts were surveyed more detailed, and following results were received. Overwhelming majority (77 percent) were resources describing hemp raising and processing. Besides information and popularization these sites contained interactive means of involving in drug use such as chats and forums where narcotists and just concerned persons could communicate and exchange experiences. The majority of these resources had a promotion banners and getting one person reach all drug net. It should be mentioned that resources contained advices and manuals for avoiding prosecution and criminal liability. Every person could find recommendations of how to create own illicit drug spreading net and involve into new victims in drug usage.

In 2012 it was decided to repeat our survey. Analysis of request "make drugs" that 79 percent of links showed by "yandex" were just media-sites and there was just one case of drugs unintentional promotion. But number of sites intentionally propagandized drugs grew to 16 percent and among them not only drug addict dictionary but other harmful resources. It should be mentioned that 3 percent were sites with information about making and selling of drugs. For example, site of drug addicts (http://cannabis.alfamoon.com/issledovaniya.html) contained books with conspicuous titles there were "Hemp encyclopedia", "Marijuana is forbidden cure", "Book of a psychogenic remedy", "Cookbook of an anarchist" including recipes of drugs, drug slogans and lists of injurious medicines unprohibited by law yet. Due to such sites drug dealers move one step forward before legislators. Because even some remedy will be forbidden all comers of drug sites can find information about other unprohibited drugs. It threatens the younger generation with promotion of new carefree style of life; these sites claim that drug using is just sacral practice or indicator of elite gathering. For example, ecstasy use, which is found more among young people and associated with particular lifestyle and events (parties, nightclubs and dance events) seen in many affluent societies (United Nations Office on Drugs and Crime, 2010).

According to received data the Internet sites aimed at drug addicts become more accessible for the last seven years. The Russian Internet develops very fast and together with it drug addict sites develop. Received data doesn't mean that number of harmful drug resources increase but it becomes simpler to find these sites. It shows us that if somebody wants to get information about drugs he can find hazard information more often than before.

Also it was interesting what society thinks about the presence of this information in the Internet. 363 persons 
divided into three groups according to their skills in using a computer were questioned in 2006. Respondents were asked about the information making possible to produce drugs at home. First question was "Do you consider that information making possible to produce drugs at home is harmful?" And more skilled in using a computer persons said in 88,19 percent that "yes, it is harmful", it was 79,19 percent in less skilled group (It was also big group of people who didn't use the Internet in 2006 and it was 90,8 percent of affirmative answers in this group).

Second question was "Is it needed to institute crime liability for spreading of the information making possible to produce drugs at home?" Skilled group in 70,08 percent of cases confirmed that it is needed to establish crime liability for spreading such harmful information and there were 75,84 percent in less skilled group.

\section{Discussion}

Why is it so attractive using the Internet by narcotists and drug dealers? What advantages does it give to offenders? We think there are some definite reasons.

The first, the Internet helps offender to avoid prosecution because it is difficult to find some anonym who posts messages in the net. It isn't needed to show passport or other personal identification documents to publish something in the Internet as on the opposite to newspaper or magazine. Malefactor can be from the other country and outside jurisdiction of a prosecutor. For instance, in Russia five years ago was published book about wonderful features of marijuana and the most of features were fake and the Russian drug police withdrew this book from use but you could find this book in the Russian-language Internet everywhere. It is also increased by common legal nihilism in Russian society (Miroshnichenko, 2014). It should be noted that absence of punishment provokes people to new illegal actions (Basova, 2014).

The second, there are no editors and censors, no necessity to post true. It is possible to publish unverified and doubtful data. Sometimes offenders intentionally distort information to involve new victims, for example, discussing imaginary medical effects but keep silent about hazards of drug usage. For example, during our research we found the sites claiming that drug addiction is fiction and everybody was able to stop at any point. They supported their conclusions by false statistics.

The Third, the Internet gives enormous speed of spreading data. Process of prohibition of new psychogenic remedy takes a lot of time it is possible drug dealer can spread to all world information about this remedy before became forbidden. Often legislator plays a "tag" with drug community because new harmful medicines became well-known every day due to the Internet and it is obliged just to ban drug which popularity is over.

The Fourth, the Internet provides avoiding of a social control. Drug usage isn't crime in the majority of countries but every drug addict has social pressure because his behavior condemned by people around him. For example, if somebody interests in drugs and asks people around about it probably he get information about hazard of drugs and advices don't attempt use drugs. Other situation in the Internet because he just alone, nobody condemns him and gives timely advice. Person can keep his damnable conduct secret. The Internet became most usable environment to spreading illegal and damnable information. Some researchers in Russia defined that the Internet got first place in spreading child porn (Donchenko, 2010), racist slogans (Dremliuga, 2008), slander (Rassolov, 2009), hacker subculture (Dremliuga, ) and e.t.c.

The fifth, possibilities of the Russian prosecutors are very limited. During last four years we have the same number of registered computer crimes. It means that we reached the limit of revealing computer crimes by our authorities.

And finally, global network makes possible to spread the information to all world in spite of borders and distances. Many offenders who create Russian-language resources to commit crimes place their sites beyond Russia (Dremliuga, 2008). It is a cheap, safe method, any drug addict can get information about drug everywhere in the net.

\section{Conclusion}

Probably fighters against drug addiction underestimate bad influence of the Internet. The Internet provides new opportunities cardinally different from existing before for drug addicts and drug dealers. There are many harmful available resources that become more popular in the Russian-language Internet. We pay more attention to this problem because the Internet penetrates into all spheres of human life and new generation get information rather from the global net than from other media. The official statistics doesn't show a real picture of drug addiction dynamic and a researcher should use new methods of research. In some sense it was a test of new way of investigation but this test helps to get some interesting results described above. Research points at real threat issued from the Internet that claims more social attention. 


\section{References}

Aloyan A.A. (2002). Prevention of the drug subculture spreading among youth social environment. PhD (Law) dissertation. Written on Russian language.

Basova T.B. (2014) Bribery situation and structure in Russia in terms of criminal statistics // Criminology Journal of Baikal National University of Economics and Law. Issue 2, 2014, Pages 23-32.

Boeri M.W., Gibson D., Harby L. (2009). Cold cook methods: An ethnographic exploration on the myths of methamphetamine production and policy implication. International journal of Drug Policy. 20. 438-443.

Forsyth A.J.M. (2012). Virtually drug scare: Mephedrone and the impact of the Internet on drug news transmission. International journal of Drug Policy. 23. 198-209.

McElrath K. O'Neill C. (2011). Experiences with mephedrone pre- and post-legislative controls: Perceptions of safety and sources of supply. International journal of Drug Policy. 22. 120-127.

Miroshnichenko O. (2014) Legal mentality as a means to overcome formal legal nihilism in Russian society // Asian Social Science. Volume 10, Issue 19, 29 September 2014, Pages 169-172. DOI: 10.5539/ass.v10n19p169.

Romanova L.I. (2008). Situation On Drugs in the Russian Federation and the Russian Far East. Justitias Welt. http://www. justitiaswelt.com/Aufsaetze/AS10_200809_LR.html.

Tupper K.W. (2008). The globalization of ayahuasca: Harm reduction or benefit maximization? International journal of Drug Policy. 19. 297-303.

United Nations Office on Drugs and Crime. (2010). World drug report 2010. New York: United Nations ISBN: 978-92-1-1-148256-0.

Donchenko A.G. (2010). Crime and other law measures to predict illegal circulation of pornography. PhD (Law) dissertation. Written in Russian Language.

Dremliuga R.I. (2008). Internet - criminality. Monograph written in Russian Language.

Dremliuga R. Subculture of hackers in Russia // Asian Social Science. Volume 10, Issue 18, 22 August 2014, Pages 158-162. DOI: 10.5539/ass.v10n18p15

Rassolov I. M. (2009). The Internet and the law. Theoretical issues. Monograph written in Russian Language. 